\title{
Avoiding second donor site and the second set of neck vessels in a case of absent peroneal skin perforators
}

\author{
Aditya Narayan Choudhary ${ }^{1}$, Rajan Arora ${ }^{1}$, Kripa Shanker Mishra ${ }^{1}$, Ravi Kiran Naalla ${ }^{1}$, Saket Srivastava ${ }^{1}$, \\ Ajay Kumar Dewan ${ }^{2}$ \\ 'Department of Reconstructive and Microvascular Surgery, Rajiv Gandhi Cancer Institute and Research Centre, Rohini, New Delhi \\ 110085, India. \\ ${ }^{2}$ Department of Surgical Oncology, Rajiv Gandhi Cancer Institute and Research Centre, Rohini, New Delhi 110085, India.
}

\begin{abstract}
Correspondence to: Dr. Kripa Shanker Mishra, Department of Reconstructive and Microvascular Surgery, Rajiv Gandhi Cancer Institute and Research Centre, Rohini, Sector-5, New Delhi 110085, India. E-mail: drksmishra25@gmail.com
\end{abstract}

How to cite this article: Choudhary AN, Arora R, Mishra KS, Naalla RK, Srivastava S, Dewan AK. Avoiding second donor site and the second set of neck vessels in a case of absent peroneal skin perforators. Plast Aesthet Res 2022;9:3.

https://dx.doi.org/10.20517/2347-9264.2021.68

Received: 17 Jun 2021 First Decision: 12 Oct 2021 Revised: 12 Nov 2021 Accepted: 24 Nov 2021 Punlished: 14 Jan 2022

Academic Editors: Matthew Spector, Mark K. Wax Copy Editor: Xi-Jun Chen Production Editor: Xi-Jun Chen

\begin{abstract}
This report describes the procedure of a case in which the skin paddle of the free fibula flap derived its supply solely from a soleal musculocutaneous perforator originating from the posterior tibial system. In contrast, the osteo-muscular component was supplied by the peroneal vascular system. We harvested the skin paddle with its vascular supply from the posterior tibial artery separately, and the osteo-muscular fibula was harvested with its supply from peroneal vessels. In this way, we avoided violation of the second donor site for the skin paddle. In addition, we used the distal end of peroneal vessels to salvage our skin paddle instead of sacrificing another set of neck vessels for anastomosis. This technique may also be utilised in cases where the neck vessels may not be available due to previous surgeries, radiation therapy, or decision by the surgery team to not sacrifice two sets of neck vessels for anastomosis.
\end{abstract}

Keywords: Free fibula flap, peroneal vessels, posterior tibial vessels, mandible reconstruction, flaps in series 


\section{INTRODUCTION}

The free fibula flap has become one of the most commonly used vascularized bony flaps to reconstruct bony defects in the body ${ }^{[1]}$, particularly the mandible. It has a reliable blood supply and a sizable bone stock. It enables the surgeon to harvest bone, skin, muscle, and fascia together and manipulate these components to tailor them for various defects.

The peroneal vessel provides vascularity to both the skeletal and the cutaneous components. The fibula receives its blood supply through the nutrient artery and periosteum, and at the same time, the skin is perfused by septocutaneous/musculocutaneous perforators. Rarely, these skin perforators may arise from posterior or anterior tibial vessels ${ }^{[2]}$.

Here we present a peculiar case where lateral leg skin perforators originated from only the posterior tibial vessels.

\section{CASE REPORT}

A 64-year-old male was diagnosed with squamous cell carcinoma at the right lower gingivobuccal sulcus by our head and neck oncology team. The surgical plan was right segmental mandibulectomy with bilateral modified neck dissection and reconstruction with free fibula osteo-musculocutaneous flap. The fibula flap harvest started through the anterior approach. Perforator dissection revealed that its origin was from the posterior tibial artery rather than peroneal artery.

The skin paddle was harvested on this perforator separately. The perforator was dissected untill its origin from the posterior tibial artery was reached. The total length of this pedicle was around $8 \mathrm{~cm}$. After considering the short pedicle length, we decided to anastomose it with the distal end of the fibula. The skin paddle was designed in eccentric fashion and the short limb was kept towards the distal end of the fibula for easy anastomosis. In this whole process, the posterior tibial vessels were left intact and limb vascularity was not compromised anywhere. At the same time, the required fibula along with the flexor hallucis longus muscle was raised on the vascular pedicle of the peroneal vessels [Figure 1]. Single osteotomy was done in the parasymphyseal region to contour the fibula in accordance with the bone defect. The bone was fixed using mini-recon plates and screws.

After bony fixation, the proximal end of the peroneal artery was anastomosed end-to-end to the right superior thyroid artery using intermittent 9-0 nylon sutures [Figure 2]. Out of the two venae comitantes, the one with the best outflow was anastomosed end to end to the common facial vein using a $3 \mathrm{~mm}$ coupler.

The skin flap vascular pedicle was anastomosed to the osteo-muscular flap in series. The arterial anastomosis was performed to the distal end of the peroneal artery in an end-to-end manner using intermittent nylon 9-0 sutures [Figure 3]. The venae comitantes of the skin paddle were anastomosed endto-end to the peroneal venae comitantes. Both flaps were well perfused at the end of the procedure.

In follow-up period, both the donor leg and flap recipient sites healed uneventfully [Figures 4-6].

\section{DISCUSSION}

Taylor et al. ${ }^{[3]}$ evaluated microvascular fibula flaps used to reconstruct tibial bone gaps. The work of Wei et al.$^{[4]}$ established the reliability of the skin paddle of the osteo-septocutaneous fibula flap. Since then, the skin has served a critical role as a cutaneous component. It serves a dual purpose, reconstruction of the 


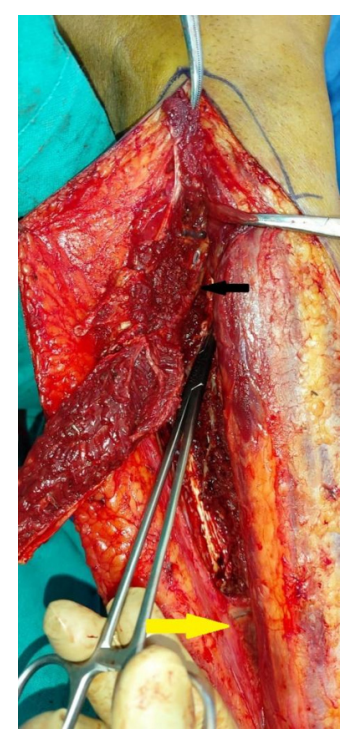

Figure 1. Black arrow: supply to the bony component of free fibula flap from the peroneal artery. Yellow arrow: septocutaneous perforator from posterior tibial vessels.

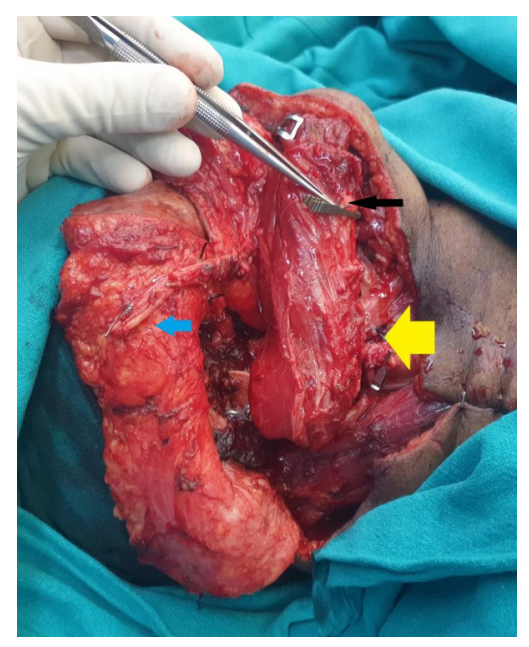

Figure 2. Black arrow: the distal end of peroneal vessels. Yellow arrow: anastomosis between superior thyroid artery and the proximal end of peroneal artery. Blue arrow: perforator to skin paddle, dissected to its origin.

defect as well as monitoring of the bone component ${ }^{[4]}$. In 1989, Hidalgo ${ }^{[5]}$ was the first to report a series of vascularized fibula flaps for mandibular reconstruction. Common vascular supply to the skin paddle of the flap is through the septocutaneous perforators ${ }^{[4]}$ arising from the peroneal vessels. There is considerable variation in the number, course, and origin of these perforators ${ }^{[6,7]}$.

Previously, authors that have encountered a situation similar to ours did one of the following:

1. Returned the skin paddle to the lower limb and used only the bony component for reconstruction ${ }^{[7]}$.

2. Performed two separate sets of anastomoses to the neck vessels ${ }^{[8-10]}$.

3. Used fibula for bony reconstruction and used another flap for skin and soft tissue from different donor sites $^{[11]}$. 


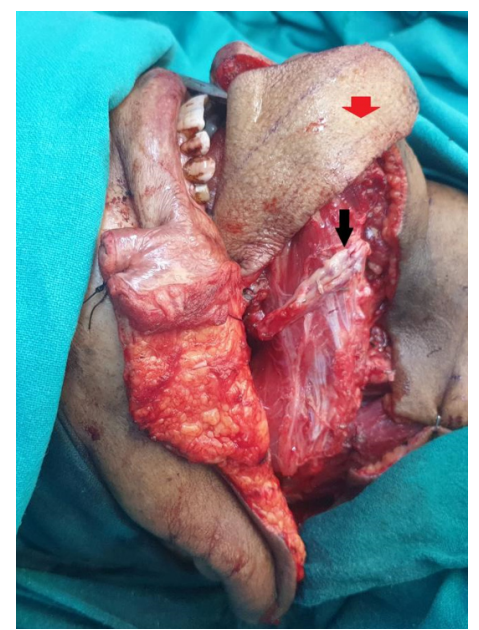

Figure 3. Black arrow: anastomosis between the distal end of peroneal vessels and the proximal end of the perforator to the skin paddle. Red arrow: skin paddle.

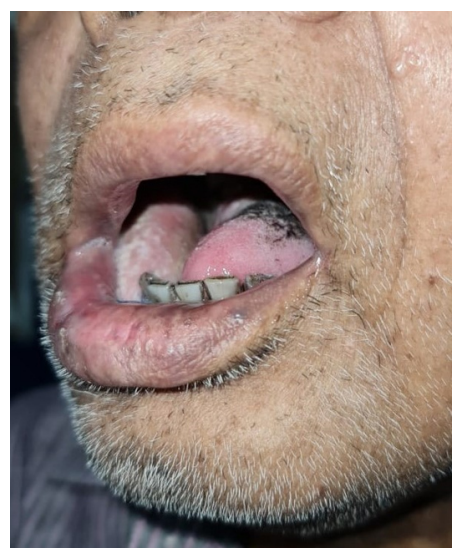

Figure 4. Intra-oral view of viable flap, six weeks follow-up.

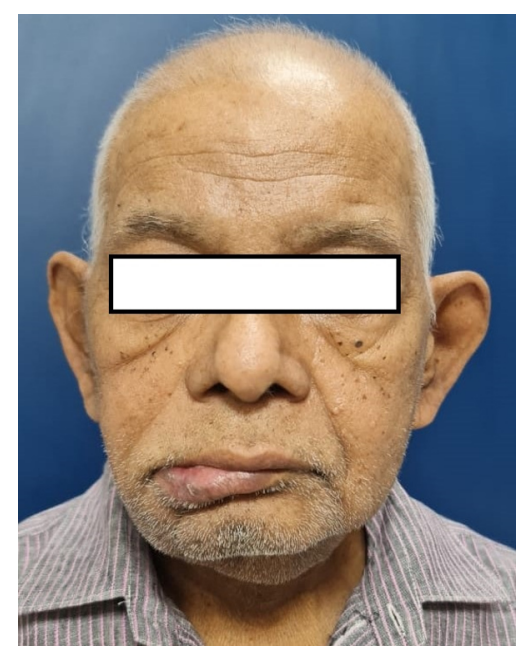

Figure 5. Frontal view of patent with good aesthetic outcome, six weeks follow-up. 


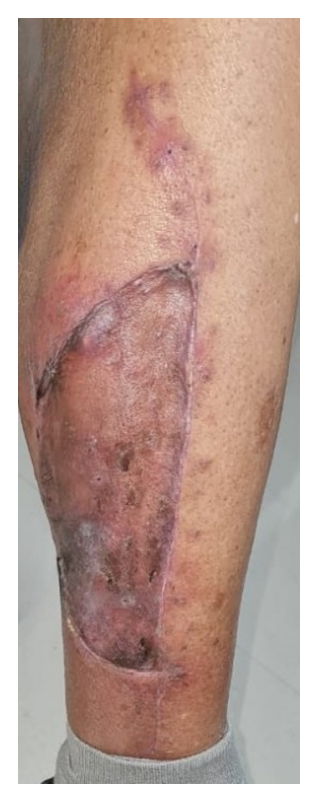

Figure 6. Well healed donor area of leg, six weeks follow-up.

In our case, we used skin paddle based on perforator of posterior tibial vessels as a second free flap from a single donor site. The distal end of the peroneal vessels was used for anastomosing vesesls of the skin paddle without sacrificing another set of neck vessels for anastomosis.

Two lessons learned from this case:

(1) Harvesting bone and skin paddle as a separate free flap can save another potential flap donor area from being wasted.

(2) The distal end of the peroneal vessels can be used as a recipient for a second free flap in vessel depleted neck.

\section{DECLARATIONS}

\section{Authors' contributions}

Drafting of the manuscript, important intellectual content, and technical support: Choudhary AN

Drafting of the manuscript and critical revision of the manuscript: Arora $\mathrm{R}$

Drafting of the manuscript and critical revision of the manuscript for important intellectual content:

Mishra KS

Drafting of the manuscript and technical support: Nalla RK, Srivastava S

Drafting of the manuscript and supervision of the manuscript: Dewan AK

\section{Availability of data and materials}

Not applicable.

\section{Financial support and sponsorship}

None.

\section{Conflicts of interest}

All authors declared that there are no conflicts of interest. 


\section{Ethical approval and consent to participate}

The study was performed following the Declaration of Helsinki. Appropriate consents were taken. The approval for the study was waived off by the ethical committee of Rajiv Gandhi Cancer Institute and Research centre, Rohini, as the case was a part of the routine care.

\section{Consent for publication}

Valid, detailed, informed, and written consent for publication was obtained from the patient.

\section{Copyright}

(c) The Author(s) 2022.

\section{REFERENCES}

1. Shanker MK, Rajan A, Hemant B, Kumar DA. Outcome of 1000 free flap head and neck reconstructions at a tertiary cancer care institute in India. Eur J Plast Surg 2021;44:25-32. DOI

2. Yadav PS, Ahmad QG, Shankhdhar VK, Nambi GI. Skin paddle vascularity of free fibula flap - a study of 386 cases and a classification based on contribution from axial vessels of the leg. Indian J Plast Surg 2012;45:58-61. DOI PubMed PMC

3. Taylor GI, Miller GD, Ham FJ. The free vascularized bone graft. A clinical extension of microvascular techniques. Plast Reconstr Surg 1975;55:533-44. DOI PubMed

4. Wei FC, Chen HC, Chuang CC, Noordhoff MS. Fibular osteoseptocutaneous flap: anatomic study and clinical application. Plast Reconstr Surg 1986;78:191-200. DOI PubMed

5. Hidalgo DA. Fibula free flap: a new method of mandible reconstruction. Plast Reconstr Surg 1989;84:71-9. PubMed

6. Kawamura K, Yajima H, Kobata Y, Shigematsu K, Takakura Y. Clinical applications of free soleus and peroneal perforator flaps. Plast Reconstr Surg 2005;115:114-9. PubMed

7. Tan BK, Wong CH. An anomalous septocutaneous perforator to the skin paddle of the fibula osteocutaneous flap originating from the posterior tibial artery. J Plast Reconstr Aesthet Surg 2009;62:690-2. DOI PubMed

8. Weber RA, Pederson WC. Skin paddle salvage in the fibula osteocutaneous free flap with secondary skin paddle vascular anastomosis. J Reconstr Microsurg 1995;11:239-41; discussion 242-4. DOI PubMed

9. Yokoo S, Komori T, Furudoi S, Umeda M, Nomura T, Tahara S. Rare variant of the intrasoleus musculocutaneous perforator: clinical considerations in raising a free peroneal osteocutaneous flap. J Reconstr Microsurg 2001;17:225-8. DOI PubMed

10. Yadav PS, Ahmad QG, Shankhdhar VK, Nambi GI. Successful management of free osteocutaneous fibula flap with anomalous vascularity of the skin paddle. Indian J Plast Surg 2009;42:255-7. DOI PubMed PMC

11. Winters HA, de Jongh GJ. Reliability of the proximal skin paddle of the osteocutaneous free fibula flap: a prospective clinical study. Plast Reconstr Surg 1999;103:846-9. DOI PubMed 